was as critical of the Lord President of the Council's office as he was of the limitations of the Ministry of Education. Pointing out that the Department of Scientific and Industrial Research in practice deals only with a comparatively small part of the nation's research and that the bulk of research sponsored or paid for by the Government does not come under the Lord President, Sir Hugh again emphasized that no means exist to formulate or to secure a coordinated national policy of research. He did not discuss how this responsibility could be discharged, but expressed the opinion that neither the Lord President of the Council nor the Department of Scientific and Industrial Research is well placed to further a coherent policy of education, research, development and finance. We are not spending enough on research and we are also lagging in the application of its results, and both can be attributed in part to the absence of scientific training among administrators and legislators. The effective mobilization of scientific effort is a problem which requires immediate attention.

\section{Underground Constructions in Sweden}

IN 1940 Sweden embarked on a series of underground works dictated mainly by the need to defend herself against possible air attack from Nazi Germany or the Allies. For some years the Government had been considering 'going underground'; a number of pilot schemes had proved successful, but the tremendous potential, both for civil and military use, of her underlying strata of igneous rock was not fully appreciated until the end of the Second World War. With solid rock strata just below the surface or outcropping, surface building in towns always involved heavy blasting or drilling. Eleven years ago the 'Swedish method' of rock drilling was made possible by the Atlas-Copco Compeny in Stockholm. With the advent of the new drill technique it became cheaper to build below ground than above. The secret of this technique lies mainly in the design of a new drill operated by compressed air. The whole drill, pusher leg and various steels, can be carried easily by one man. The effectiveness of the method can be seen in the construction of the Katarinaberget in Stockholm. This is a three-deck bomb shelter and car park with room for 20,000 people. Details of its method of construction as well as other underground buildings in Sweden have been described by Hugh Pitt in a recent issue of Discovery $(18$, No. 2; February 1958). In the same issue Com. C. H. Williarns describes all the ships which have carried the famous name Discovery.

\section{A New Journal of Geophysics}

THE first number of the Geophysical Journal (The Geophysical Journal of the Royal Astronomical Society, incorporating the Geophysical Supplement to the Monthly Notices of the R.A.S. Vol. 1, No. 1 (March 1958). Pp. 114. Published quarterly. Annual subscription : 608 . ; 9 dollars ; single issues : 208 , ; 3 dollars. (London: Royal Astronomical Society, 1958)) replaces, and in fact incorporates, the Geophysical Supplement of the Monthly Notices of the Royal Astronomical Society. It is to be published regularly four times a year and it will contain original contributions on various aspects of geophysics similar to those which were published in the Geophysical Supplement. The scope of the contents, however, will exceed that of the original supplement and it is intended to publish brief review articles on modern developments in those subjects in which recent research has produced new and important data. At the same time it will give summaries of the proceedings of the more important meetings on geophysical topics, including the Geophysical Discussions of the Royal Astronomical Society itself. Thus, in the present issue there are summaries of symposia on gravity measurements at sea, palæomagnetism and fault plane conditions held in connexion with the recent Eleventh General Assembly of the International Union of Geodesy and Geophysics in Toronto.

Inspection of the original contributions, which embrace the Earth's interior, various aspects of seismology, gravity, terrestrial magnetism including palæomagnetism and the mechanical properties of rocks, demonstrates that the same high standard characteristic of its predecessor is well maintained. This, coupled with its wider field of interest, should ensure the success of this new venture since its contents will appeal to both academic and applied geophysicists. Finally, an innovation worthy of comment is the inclusion at the end of the number of the titles and summaries of all the original contributions translated into Russian.

\section{National Museum of Wales}

THE annual report of the National Museum of Wales for $1956-57$ (pp. $76+4$ plates. Cardiff: National Museum of Wales, 1957) naturally gives prominence to a record of the jubilee celebrations of March 1957. On the fiftieth anniversary of the date on which the Charter of Incorporation was granted (March 19) there were broadcasts in Welsh and English on the Museum and its activities, and a reception attended by more than 800 guests. A jubilee exhibition was arranged and a booklet outlining the history of the Museum was published. A memorial plaque to the late Dr. V. E. Nash-Williams was also unveiled in March 1957. A renewed application to the Treasury for the necessary funds to begin a Department of Industry was unsuccessful, but it is encouraging to note that, nothing daunted, the Council has submitted a third application. The circular gallery is again free for temporary exhibitions and it is a tribute to the Director and his staff that seventeen exhibitions were shown during the year. At St. Fagan's the first floor of the new museum building has been arranged to show a cross-section of the Welsh folk collection, and statistics give details of the intra- and extra-mural services of the Museum Schools Service.

\section{Museum and Art Gallery, Leicester}

THE fifty-first annual report of the Leicester Museum and Art Gallery for 1956-57 (pp. $43+4$ plates. Leicester: The Museums and Art Gallery, 1957) reports many activities of this lively centre. The repairs to Newarke Houses which have been spread over so many years have been completed, and the Chantry House opened as a Museum of the Medieval History of Leicester. The Committee has obtained the tenancy of 50 St. Nicholas Street, and has taken steps, while plans for the use of the building as a terching museum of Roman history are developed, to make the important Roman pavement in the basement available to the public. Plans for the completion of the Jewry Wall site were again postponed for financial reasons. The committee thanks $\mathrm{Mr}$. P. A. H. Muschamp for his invaluable honorary daily work in the Entomological Department during the past thirty-eight years. 